\title{
OPTIMASI DESAIN BILAH DENGAN METODE LINEARISASI CHORD DAN TWIST TERHADAP PERFORMA TURBIN ANGIN SUMBU HORIZONTAL
}

\author{
Bramandhika Augustiantyo \\ Fakultas Teknik, Program Studi Teknik Mesin \\ Universitas Singaperbangsa Karawang \\ Email:1710631150057@student.unsika.ac.id \\ Reza Setiawan \\ Fakultas Teknik, Program Studi Teknik Mesin \\ Universitas Singaperbangsa Karawang \\ Email: Reza.setiawan@staff.unsika.ac.id \\ Oleh \\ Fakultas Teknik, Program Studi Teknik Mesin \\ Universitas Singaperbangsa Karawang \\ Email: Oleh@staff.unsika.ac.id
}

\begin{abstract}
ABSTRAK
Turbin angin merupakan salah satu alat konversi ramah lingkungan dengan salah satu komponen utamanya adalah bilah. Dalam optimasi bilah perlu diperhatikan beberapa parameter yaitu chord dan twist. Rancangan desain yang tepat akan menghasilkan bilah yang memiliki performa yang baik. Metode yang digunakan dalam penelitian ini adalah metode simulasi dengan bantuan perangkat lunak. Perangkat lunak yang digunakan adalah Microsoft Excel dan Qblade. Adapun target yang ingin dicapai pada penelitian ini yaitu mencari desain bilah yang terbaik dengan cara optimasi menggunakan metode linearisasi chord dan twist, hasil akhirnya akan didapat grafik performansi Coefficient power (Cp) dan Tip speed ratio (TSR). Berdasarkan hasil penelitian yang telah dilakukan mendapatkah hasil bahwa bilah airfoil SG6043 Taper dengan distribusi twist dari hub adalah sebesar 10.77 hingga ujung sebesar 0.91 dan distribusi chord adalah sebesar $0.120 \mathrm{~m}$ pada bagian $h u b$ dan $0.042 \mathrm{~m}$ pada bagian pangkal. Hasil pengujian variasi linearisasi chord dan twist didapat bahwa titik linearisasi twist pada 55\% dan chord pada $25 \%$ menghasilkan coefficient power $(\mathrm{Cp})$ sebesar $52.6 \%$ dengan Tip speed ratio optimal sebesar 4.5.
\end{abstract}

Kata Kunci : turbin angin skala mikro, koefisien daya (Cp), tip speed ratio (TSR), bilah turbin, perangkat lunak Qblade

\section{ABSTRACT}

Turbine is one of the eco-friendly conversion machines with one of the main components is the blade. In optimizing the blade, it is necessary to pay attention to several parameters, namely chords and twists. The right design design will produce blades that have good performance. The method used in this research is the simulation method with software. The software used is Microsoft Excel and Qblade. The target to be achieved in this study is to find the best blade design in an optimal way using the chord and twist linearization method, the result will be a performance graph of the Coefficient power (Cp) and Tip speed ratio (TSR). Based on the results of the research that has been done, the results show that the SG6043 Taper airfoil blade with a twist distribution from the hub is 10.77 to the tip of 0.91 and the chord distribution is $0.120 \mathrm{~m}$ at the hub and $0.042 \mathrm{~m}$ at the base. The results of the test for the variation of chord and twist linearization showed that the point of 
lineization of twist at $55 \%$ and chord at $25 \%$ resulted in a Power coefficient (Cp) of $52.6 \%$ with an optimal tip speed ratio of 4.5 .

Keywords: micro-scale wind turbines, Power coefficient (Cp), tip speed ratio (TSR), turbine blades, Qblade software

\section{PENDAHULUAN}

Listrik adalah salah satu kebutuhan utama dikehidupan ini. Dengan adanya listrik kita bisa mengoperasikan perangkat elektronik yang ada dikehidupan sehari-hari. Seiring berjalannya waktu, permintaan listrik selalu meningkat dibandingkan dengan jenis energi lainnya. Sektor kelistrikan dapat meningkatkan aktivitas ekonomi diatas rata-rata, meningkatkan pendapat nasional negara dan meningkatkan kesejahteraan masyarakat [1].

Pertumbuhan listrik pada tahun 2050 dipastikan naik hampir 9 kali lipat. Sesuai PP No.79 Tahun 2014 tentang Kebijakan Energi Nasional, indonesia memiliki target bauran EBT paling sedikit $23 \%$ pada tahun 2025 dan $31 \%$ pada tahun 2050. Saat ini indonesia telah memanfaatkan EBT sebesar $14 \%$ pada tahun 2018. Minimnya pengembangan serta pemanfaatan EBT masih relatif tinggi dikarenakan sulit bersaing dengan pembangkit fosil seperti batubara dan kurang didukungnya industri dalam pendanaan hingga pengembangan EBT ini [2].

Secara geografis indonesia merupakan negara kepulauan yang memiliki iklim tropis dan kecepatan angin itu sendiri ada direntang $2 \mathrm{~m} / \mathrm{s}-6 \mathrm{~m} / \mathrm{s}$ yang termasuk kecepatan angin minimum [3]. Dalam hal ini indonesia memiliki keuntungan untuk mengembangkan pembangkit listrik dengan memanfaatkan angin. Angin dapat mempengaruhi performa dari turbin salah satunya pada bagian bilah turbin itu sendiri. Bilah atau Propeller merupakan salah satu komponen terpenting dalam mendesain turbin angin, bilah secara langsung menjadi bagian transisi untuk merubah angin menjadi energi gerak berupa putaran poros lalu disalurkan kepada generator untuk mengubahnya menjadi energi dalam bentuk listrik.

Di indonesia sudah ada yang mengembangkan dan meriset angin dengan cara pemanfaatan energi angin menggunakan media turbin angin skala mikro. PT. Lentera Bumi Nusantara terletak di bagian selatan jawa barat tepatnya pesisir tasikmalaya. Namun turbin angin akan memiliki kemampuan berbeda-beda dalam menangkap energi angin. Salah satunya adalah komponen bilah yang merupakan komponen utama dalam mengekstrak energi angin tersebut. Oleh karena itu perlu dilakukan penelitian/riset mendalam mengenai bilah turbin angin sehingga mendapatkan performa yang tinggi dan dapat menyerap angin secara maksimal.

Berdasarkan hal tersebut penulis ingin melakukan penelitian untuk mengoptimasi perancangan bilah dengan menggunakan metode variasi linearisasi chord dan twist angle pada turbin angin sumbu horizontal menggunakan software Microsoft Excel untuk pengolahan data. Lalu dianalisa menggunakan Qblade untuk melihat performa bilah yang terjadi pada turbin angin tersebut. Dengan harapan penelitian ini dapat menjadi acuan dalam perancangan bilah turbin angin.

Angin merupakan salah satu energi dan dibuktikan dalam Hukum kekekalan energi yang menyatakan bahwa energi itu tidak dapat diciptakan maupun dimusnahkan, tetapi dapat diubah dari satu bentuk ke bentuk lainnya. Untuk mengubah energi angin maka dibutuhkan suatu alat konversi seperti turbin angin. Turbin angin mengubah energi angin menjadi putaran lalu disalurkan ke dalam roda gigi (jika memakai gearbox) atau ke dalam generator untuk diubah selanjutnya menjadi listrik berupa fasa AC. Karena angin adalah suatu energi, maka energi angin dapat dinyatakan sebagai energi kinetik yaitu sebagai berikut :

Dimana :

$$
\mathrm{E}_{\mathrm{K}}=\frac{1}{2} \mathrm{mv} v^{2}
$$

$$
\begin{array}{ll}
\mathrm{E}_{\mathrm{K}} & =\text { Energi kinetik }(\mathrm{J}) \\
\mathrm{m} & =\text { Massa benda }(\mathrm{kg})
\end{array}
$$




$$
\mathrm{v} \quad=\operatorname{Kecepatan}(\mathrm{m} / \mathrm{s})
$$

Berdasarkan formula diatas, maka daya sama dengan jumlah energi per satuan waktu sehingga daya angin dapat dinyatakan dalam bentuk berikut :

$$
\mathrm{P}_{\text {angin }}=\frac{1}{2} \rho A v^{3}
$$

Dimana :

$$
\begin{array}{ll}
\mathrm{P}_{\text {angin }} & =\text { Daya angin }(\mathrm{W}) \\
\rho & =\text { Densitas udara }=1,225\left(\mathrm{~kg} / \mathrm{m}^{3}\right) \\
\mathrm{V} & =\operatorname{kecepatan} \text { udara }(\mathrm{m} / \mathrm{s}) \\
\mathrm{A} & =\text { luas sapuan bilah }\left(\mathrm{m}^{2}\right)
\end{array}
$$

\begin{tabular}{|c|c|c|}
\hline \multicolumn{3}{|c|}{ Tingkat Kecepatan Angin 10 meter diatas permukaan atas } \\
\hline No & Kecepatan & Kondisi Alam di Daratan \\
\hline 1 & $0.00-0.02$ & …................ \\
\hline 2 & $0.3-1.5$ & Angin tenang \\
\hline 3 & $1.6-3.3$ & Asap bergerak \\
\hline 4 & $3.4-5.4$ & Daun bergoyang \\
\hline 5 & $5.5-7.9$ & Ranting bergoyang \\
\hline 6 & $8.0-10.7$ & Bendera berkibar \\
\hline 7 & $10.8-13.8$ & Air bergerak \\
\hline 8 & $13.9-17.1$ & Ujung pohon melengkung \\
\hline 9 & $17.2-20.7$ & Jalan berat melawan arah angin \\
\hline 10 & $20.8-24.4$ & Rumah rubuh \\
\hline 11 & $24.5-28.4$ & Pohon rubuh \\
\hline 12 & $28.5-32.6$ & Menimbulkan kerusakan parah \\
\hline 13 & $32.7-36.9$ & Tornado \\
\hline
\end{tabular}

Proses pemanfaatan angin dapat dilakukan dua tahap. Pertama hembusan angin akan menggerakan rotor hingga berputar. putaran rotor tersebut terhubung dengan generator, output yang dihasilkan dari generator inilah yang akan digunakan berupa arus listrik. Untuk melihat potensi dari kondisi angin tersebut bisa dilihat pada tabel 1 [4].

Tabel 1. Klasifikasi Kecepatan Angin [4]

Klasifikasi angin pada skala $1.6 \mathrm{~m} / \mathrm{s}$ hingga $3.3 \mathrm{~m} / \mathrm{s}$ adalah batas minimum dan angin pada skala $13.9 \mathrm{~m} / \mathrm{s}$ hingga $17.1 \mathrm{~m} / \mathrm{s}$ adalah batas maksimum energi angin yang dapat dimanfaatkan untuk menghasilkan energi listrik.

Energi angin dapat diekstrak ke dalam bentuk lain seperti energi listrik dan energi mekanik dengan menggunakan suatu sistem konversi energi seperti turbin angin [5]. Daya adalah energi per satuan waktu dan berbanding lurus dengan kerapatan udara dan kecepatan angin, dan dapat dibentuk menjadi persamaan sebagai berikut

Dimana :

$$
\mathrm{P}=\frac{1}{2} \rho V^{3}
$$

$\mathrm{P} \quad=$ Daya angin $(\mathrm{W})$

$\rho \quad=$ Densitas udara $=1,225\left(\mathrm{~kg} / \mathrm{m}^{3}\right)$

$\mathrm{V} \quad=$ Kecepatan angin $(\mathrm{m} / \mathrm{s})$

Karena kerapatan udara memiliki perbedaan di dataran rendah dan dataran tinggi, maka energi angin di daerah pantai akan jauh lebih besar daripada di pegunungan. Ini bisa dilihat dari persamaan diatas bahwa apabila di suatu tempat memiliki kecepatan angin 2 kali lebih cepat dari tempat itu maka tempat itu memiliki energi angin sebesar 8 kali lipat lebih besar. Oleh karena itu penentuan tempat sangat mempengaruhi angin yang dapat diserap oleh turbin angin. Daya angin maksimum dapat di ekstrak oleh sistem turbin angin dengan luas sapuan rotor (A) adalah : 
Dimana :

$$
\mathrm{P}=0.59 \frac{1}{2} \rho \mathrm{A} \mathrm{V}^{3}
$$

$$
\begin{array}{ll}
\mathrm{P} & =\text { Daya angin }(\mathrm{W}) \\
\rho & =\text { Densitas udara }=1,225\left(\mathrm{~kg} / \mathrm{m}^{3}\right) \\
\mathrm{A} & =\text { Luas sapuan pada bilah }\left(\mathrm{m}^{2}\right) \\
\mathrm{V} & =\text { Kecepatan angin }(\mathrm{m} / \mathrm{s})
\end{array}
$$

Angka 0.59 ini disebut Betz Limit, angka tersebut menunjukan bahwa efisiensi maksimum yang dapat dicapai oleh suatu sistem rotor turbin angin. Pada kenyataannya karena terjadi losses gesekan dan losses pada bagian ujung tip bilah, maka efisiensi yang dapat dicapai rotor akan mendapatkan angka yang lebih kecil yaitu berkisar 0.45 pada keadaan maksimum. Maka daya yang dapat diserap oleh turbin angin sebagai berikut :

$$
\mathrm{P}=\eta \cdot \frac{1}{2} \rho \mathrm{A} \mathrm{V}^{3}
$$

Dimana :

$$
\begin{array}{ll}
\mathrm{P} & =\text { Daya angin }(\mathrm{W}) \\
\rho & =\text { Densitas udara }=1,225\left(\mathrm{~kg} / \mathrm{m}^{3}\right) \\
\mathrm{A} & =\text { Luas sapuan pada bilah }\left(\mathrm{m}^{2}\right) \\
\mathrm{V} & =\text { Kecepatan angin }(\mathrm{m} / \mathrm{s}) \\
\eta & =\text { Efisiensi Maksimum }
\end{array}
$$

Seiring berkembangnya zaman, perkembangan teknologi seperti turbin angin modern hingga saat ini memiliki kualitas 100 kali lebih kuat dibandingkan beberapa tahun yang lalu [6]. Sehingga hasilnya dapat disalurkan dengan menggunakan kabel transmisi dan dapat didistribusikan ke rumah, gedung, lampu jalan, dan lain-lain. Pada gambar 1 berikut ini adalah jenis turbin angin :

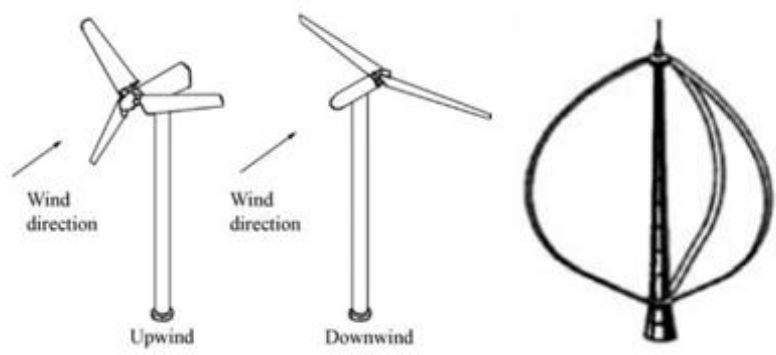

Gambar 1. Turbin Angin Sumbu Horizontal (kiri) dan Sumbu Vertikal (kanan)[7]

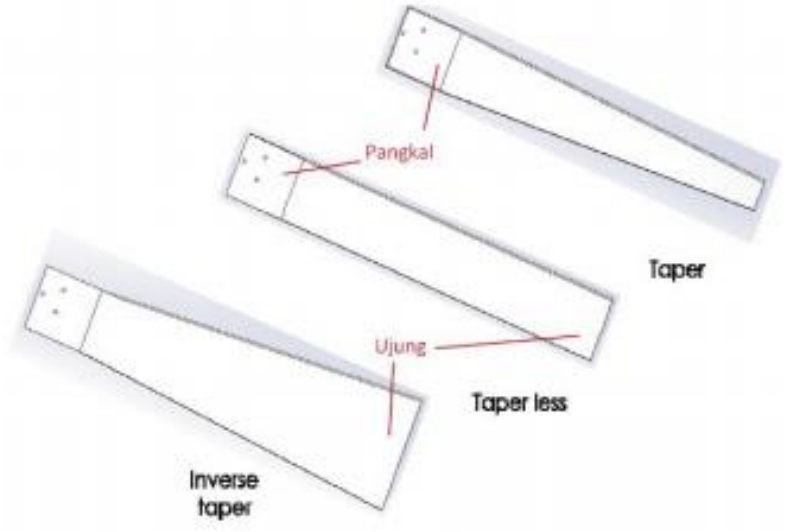

Gambar 2. Tiga jenis Bilah Turbin Angin Sumbu Horizontal [7] 
Berdasarkan jenisnya, bilah dibedakan menjadi 3 jenis yaitu sebagai berikut :

a. Taper yaitu bilah yang memiliki geometri lebar chord mengecil dari pangkal ke ujung serta cocok untuk angin berkecepatan tinggi

b. Taperless yaitu bilah yang memiliki geometri lebar chord sama dari pangkal ke ujung serta cocok untuk angin berkecepatan sedang.

c. Inverse Taper yaitu bilah yang memiliki geometri lebar chord membesar dari pangkal ke ujung serta cocok untuk angin berkecepatan rendah.

Pemilihan geometri bilah sangat penting dalam desain perancangan, karena dapat berpengaruh terhadap putaran yang diterima oleh angin pada saat menabrak luas sapuan bilah dan disesuaikan dengan kondisi angin yang ada.

\subsection{TIP SPEED RATIO}

Tip speed ratio atau biasa disebut TSR adalah angka perbandingan dari kecepatan ujung bilah terhadap kecepatan angin yang dilewati bilah untuk berputar. Nilai TSR tip speed ratio yang tinggi dan rendah akan berpengaruh terhadap turbin angin, pada saat nilai TSR $>1$ menunjukan bahwa lebih banyak bagian bilah yang mengalami gaya angkat (lift). Sedangkan jika pada saat nilai TSR < 1 maka lebih banyak bagian dari bilah yang akan mengalami gaya hambat. Untuk mendapatkan nilai tip speed ratio dapat menggunakan persamaan :

$$
\lambda=\frac{r}{R} \times \lambda R
$$

Dimana :

$$
\begin{array}{ll}
\lambda & =\text { Tip speed ratio } \\
\mathrm{r} & =\text { Tip speed ratio } \text { Parsial } \\
\mathrm{R} & =\text { Jari-Jari Parsial }(\mathrm{m}) \\
\lambda \mathrm{R} & =\text { TSR yang digunakan }
\end{array}
$$

Untuk Angka TSR yang tinggi memiliki kelebihan dalam hal koefisien daya (Cp) dan kecepatan rotor untuk berputar. Sedangkan kelemahan adalah jika digunakan pada kecepatan angin yang sangat rendah maka dibutuhkan biaya produksi yang tinggi dan memerlukan putaran awalan yang bagus. Disisi lain untuk TSR yang rendah memiliki kelebihan dalam hal torsi yang dihasilkan tinggi, dan biaya produksi yang dapat ditekan, sedangkan kelemahan dari TSR rendah yaitu koefisien yang dihasilkan akan kecil. TSR rendah juga dapat digunakan untuk kecepatan angin rendah.

\subsection{COEFFICIENT POWER (Cp)}

Koefisien daya atau lebih sering disebut Power coefficient adalah kemampuan bilah dalam menyerap energi yang diterimanya. Diasumsikan jika nilai $\mathrm{Cp}$ adalah 50\% maka kemampuan menyerap energi angin adalah $50 \%$ yang akan diteruskan menuju rotor generator, sisanya akan dibuang begitu saja. Menurut teori betz jika koefisien daya yang dihasilkan adalah 50\%, maka tidak sepenuhnya dapat diserap 50\%. Terjadi fenomena seperti itu karena $\mathrm{Cp}$ akan mengalami rugi-rugi yang berasal dari sistem. Performa dari turbin angin itu sendiri dapat dinyatakan dengan koefisien daya $(\mathrm{Cp})$, dimana :

$$
\mathrm{Cp}=\frac{\mathrm{P}}{\text { Pangin }}=\frac{\frac{1}{2} \rho \mathrm{AU}^{3} 4 \mathrm{a}(1-\mathrm{a})^{2}}{\frac{1}{2} \rho \mathrm{AU}^{3}}
$$

Dari persamaan diatas dapat disederhanakan menjadi :

$$
\mathrm{Cp}=4 \mathrm{a}(1-\mathrm{a})^{2}
$$

Dimana :

$\mathrm{Cp}=$ Coefficient Power

a $\quad=$ Induksi Aksial

Perancangan bilah dibutuhkan beberapa parameter-parameter, salah satunya adalah menentukan kapasitas energi listrik yang akan dihasilkan dan efisiensi dari sistem tersebut. Dalam 
buku "Windpower Workshop" yang ditulis oleh Piggot H. pada tahun 1997 energi angin dapat dikonversikan turbin angin dengan nilai Power coefficient (Cp) sebesar 59.3\% akan tetapi pada kenyataannya akan mengalami rugi-rugi yang berasal dari sistem seperti loss dari generator, loss Controller serta komponen lainnya dan ini berdasarkan teori betz [9].

Perancangan bilah dimulai dengan menentukan efisiensi berdasarkan asumsi yang berasal dari Qblade. Jika kita memasukan suatu airfoil maka akan muncul grafik efisiensi bilah. Seluruh nilai efisiensi tersebut dikalkulasikan berdasarkan kenyataannya, dengan asumsi bilah dan komponennya maka dapat dicari dengan mengalikan efisiensi sistem seperti $\eta$ bilah, $\eta$ transmisi, $\eta$ generator, $\eta$ controller.

Selanjutnya daya angin yang dibutuhkan untuk menghasilkan daya listrik. Diasumsikan daya listrik sebesar $500 \mathrm{~W}$, nilai daya listrik ini disesuaikan dengan generator yang dipakai yaitu TSD500 yang artinya The Sky Dancer dengan kapasitas $500 \mathrm{~W}$, maka dengan efisiensi yang telah diketahui sebelumnya maka dapat ditemukan daya angin tersebut dengan menggunakan persamaan :

Dimana :

$$
W a=\frac{W e}{K}
$$

$\mathrm{Wa} \quad=$ Daya Angin $(\mathrm{W})$

$\mathrm{We} \quad=$ Kapasitas daya listrik (W)

$\mathrm{K}=$ Efisiensi Sistem Keseluruhan

Setelah daya angin tersebut telah diketahui dari rumus tadi, selanjutnya mencari luas sapuan bilah. luas sapuan tersebut merupakan area yang akan dilewati oleh angin dan mendorong bagian bilah tersebut. Berdasarkan teori jika luas sapuan semakin besar maka energi angin yang diterima akan besar, sebaliknya jika luas sapuan semakin kecil maka energi angin yang akan kecil. Luas sapuan tersebut dapat dicari menggunakan rumus sebagai berikut :

Dimana :

$$
A=\frac{2 W a}{\rho \operatorname{vmax}^{3}}
$$

A $\quad=$ Luas sapuan bilah $\left(\mathrm{m}^{3}\right)$

$\mathrm{Wa} \quad=$ Daya angin $(\mathrm{W})$

$\rho \quad=$ Densitas udara $=1,225\left(\mathrm{~kg} / \mathrm{m}^{3}\right)$

$\operatorname{Vmax}=$ Kecepatan angin maksimum $(\mathrm{m} / \mathrm{s})$

Luas sapuan telah didapat, selanjutnya mencari jari-jari bilah. Dan dapat ditentukan menggunakan rumus sebagai berikut :

$$
R=\sqrt{\frac{A}{\pi}}
$$

$\mathrm{R} \quad=$ jari-jari bilah $(\mathrm{m})$

A $\quad=$ luas sapuan bilah $\left(\mathrm{m}^{2}\right)$

Setelah didapat jari-jari bilah, selanjutnya menentukan parameter yang akan dirancang meliputi airfoil yang dipakai, TSR, nilai $\mathrm{Cl} / \mathrm{Cd}$, nilai chord atau lebar dari bilah tersebut, dan jumlah bilah yang dipakai. Setelah ditentukan parameter tersebut maka dapat perkiraan perancangan bilah dengan mencari pembagian elemen pada bilah. Pada PT. Lentera Bumi Nusantara pembagian elemen berkisar 10 elemen, tetapi jika ingin mendapatkan nilai yang lebih spesifik bisa memakai pembagian elemen lebih dari 10. Rumus pembagian elemen tersebut dapat dituliskan sebagai berikut :

Dimana :

$$
r=0,25+\left[\left(\frac{R-0.25}{n}\right) \times(\text { elemen })\right]
$$

$\mathrm{r} \quad=$ Jari-jari parsial $(\mathrm{m})$

$\mathrm{R} \quad=$ Jari-jari yang digunakan $(\mathrm{m})$

$\mathrm{n} \quad=$ Jumlah elemen keseluruhan

Setelah didapat elemen, selanjutnya menentukan nilai Tip speed ratio untuk turbin angin. Pada buku "Windpower Workshop" yang ditulis oleh Piggot H. pada tahun 1997, dalam referensi tersebut 
dipaparkan tabel meliputi tip speed ratio, jumlah bilah, dan penggerak dari turbin itu sendiri. Dapat dilihat pada tabel 2 berikut:

Tabel 2. Nilai Tip speed ratio [11]

\begin{tabular}{lll}
\hline TSR & Jumlah Bilah & Penggerak \\
\hline 1 & $6-20$ & Slow pumps \\
2 & $4-12$ & Faster pumps \\
3 & $3-6$ & Dutch 4-bladed \\
4 & $2-4$ & Slow generator \\
$2-8$ & $2-3$ & Generator \\
$8-15$ & $1-2$ & Fastest possible \\
\hline
\end{tabular}

Untuk mencari nilai tip speed ratio parsial dapat menggunakan rumus

$$
\lambda r=\frac{r}{R} \times \lambda R
$$

Dimana :

$\lambda \mathrm{r} \quad=$ Tip speed ratio Parsial

$\mathrm{r} \quad=$ Jari-jari parsial $(\mathrm{m})$

$\mathrm{R}=$ Jari-jari yang digunakan yaitu 0.8 meter

$\lambda \mathrm{R}=$ Tip speed ratio yang digunakan yaitu 7

Selanjutnya menentukan chord karena dalam penelitian ini adalah berjenis taper dimana di tiap elemennya memiliki lebar berbeda-beda, jenis bilah taper ini dipilih dengan keadaan di lapangan yaitu $12 \mathrm{~m} / \mathrm{s}$ berdasarkan penelitian terkait potensi angin di pesisir jawa [8]. Karena angin yang digunakan adalah $12 \mathrm{~m} / \mathrm{s}$ maka berdasarkan jenis bilah yang ada, taper adalah yang paling tepat karena cocok untuk angin berkecepatan tinggi. Setelah didapat nilai tip speed ratio selanjutnya menghitung jumlah chord dengan persamaan :

$$
C l=\frac{16 \pi \times R \times\left(\frac{R}{r}\right)}{9 \lambda^{2} \times B \times C r}
$$

Dimana :

$\mathrm{B} \quad=$ Jumlah bilah yang digunakan

$\mathrm{Cr} \quad=$ jumlah $\operatorname{chord}(\mathrm{m})$

Setelah didapatkan lebar chord di setiap elemennya maka kita selanjutnya menentukan sudut aliran udara alpha dan dapat menggunakan rumus sebagai berikut :

Dimana :

$$
\emptyset=\frac{2}{3} \tan ^{-1} \frac{1}{\lambda r}
$$

$\emptyset \quad=$ Flow angle / sudut alir (Degree)

$\lambda \mathrm{r} \quad=$ Tip speed ratio parsial

Sedangkan untuk sudut aliran udara beta dapat dicari menggunakan sudut aliran udara alpha dengan melihat grafik pada software Qblade. Setelah didapat sudut aliran beta selanjutnya menghitung sudut puntir dapat dihitung menggunakan persamaan :

$$
\begin{aligned}
& \beta=\text { = Puntiran / Twist (deg) } \\
& \emptyset \quad=\text { Sudut Aliran (deg) } \\
& \alpha=\text { Angle of Attack (deg) }
\end{aligned}
$$

Nilai puntiran tersebut sangat mempengaruhi dalam perancangan bilah, karena hingga tahap ini akan mendapatkan puntiran yang sangat ekstrim maka digunakanlah linearisasi di tiap elemennya. Linearisasi dianalisa tiap elemen untuk mendapatkan karakteristik yang optimal dengan menghitung persen dari jumlah bilah tersebut. Untuk mendapatkan hasil yang lebih maksimal maka elemen harus dibagi sekecil mungkin. Hasilnya adalah linearisasi dapat mempengaruhi nilai Cp dan TSR dari bilah tersebut. Dalam penelitian ini akan dilakukan linearisasi untuk twist dan chord nya. Sebagai contoh jika ingin dilinearisasi $50 \%$ dari bilah tersebut maka titik elemen diambil dari bagian 
tengah geometri bilah. Lalu nilai tersebut didapat dari persamaan yang dikeluarkan oleh excel dan dapat dihitung untuk melihat karakteristik Cp dan TSR nya.

Bilah perlu dilakukan linearisasi karena dapat memudahkan proses manufaktur bilah. Linearisasi juga ditentukan dengan menggunakan persen per satuan panjang bilah. Berdasarkan penelitian yang telah dilakukan oleh Saoke (2015), Metode linearisasi dilakukan dengan menggunakan panjang bilah dan titik yang akan dilakukan lineariasi. Dari titik yang telah dipilih dapat diolah menggunakan beberapa aplikasi salah satunya adalah excel, karena yang akan digunakan adalah persamaan yang dikeluarkan oleh trendline grafik tersebut. Pemilihan titik untuk dilinearisasi harus dilakukan dengan sangat hati-hati karena keputusan yang buruk dapat mempengaruhi efisiensi rotor [10].

\section{METODE PENELITIAN}

Metode yang digunakan dalam penelitian ini adalah metode simulasi dengan bantuan perangkat lunak. Perangkat lunak yang digunakan adalah Microsoft Excel dan Qblade. Adapun target yang ingin dicapai pada penelitian ini yaitu mencari desain bilah yang terbaik dengan cara optimasi menggunakan metode linearisasi chord dan twist, hasil akhirnya akan didapat grafik performansi Coefficient power (Cp) dan Tip speed

\section{HASIL DAN PEMBAHASAN}

Geometri bilah memiliki parameter-parameter yang akan digunakan dalam perancangan. Ada dua parameter yang digunakan yaitu variabel tetap yang akan dihitung dan variabel bebas. variabel yang ditetapkan yaitu kapasitas daya listrik yang digunakan, efisiensi sistem (bilah, transmisi, generator, controller), jumlah bilah yang digunakan, Tip speed ratio dan karakteristik angin berdasarkan letak geografis tersebut. Sedangkan airfoil digunakan sebagai variabel bebas. Pada parameter awal ini dilakukan penentuan besar kapasitas listrik yang dibutuhkan, kapasitas listrik ini ditentukan oleh pendesain generator dan kapasitas tersebut berpengaruh terhadap ukuran dan dimensi bilah. Dalam penelitian ini digunakan daya listrik maksimal yang akan dihasilkan adalah sebesar $500 \mathrm{~W}$ pada kecepatan angin $12 \mathrm{~m} / \mathrm{s}$. Nilai daya listrik ini disesuaikan dengan generator yang dipakai yaitu TSD-500 yang artinya The Sky Dancer dengan kapasitas $500 \mathrm{~W}$, serta nilai kecepatan angin disesuaikan dengan keadaan di lapangan yaitu $12 \mathrm{~m} / \mathrm{s}$ berdasarkan penelitian terkait potensi angin di pesisir jawa [8]. Maka parameter tersebut dapat dilihat pada Tabel 3.

Tabel 3. Parameter dan Karakteristik Airfoil SG6043

\begin{tabular}{|c|c|c|c|c|c|c|c|}
\hline \multirow{2}{*}{$\begin{array}{l}\text { Kapasitas } \\
\text { daya listrik }\end{array}$} & \multicolumn{5}{|c|}{ Efisiensi } & \multirow{2}{*}{$\begin{array}{l}\text { Daya } \\
\text { angin }\end{array}$} & \multirow{2}{*}{$\begin{array}{c}\mathrm{V} \\
\max \end{array}$} \\
\hline & Bilah & Generator & Transmisi & Controller & Sistem & & \\
\hline 500 & $\begin{array}{l}0.3 \\
0.4\end{array}$ & 0.9 & 0.9 & 0.9 & $\begin{array}{l}0.219 \\
0.292\end{array}$ & $\begin{array}{l}2286.24 \\
1714.68\end{array}$ & 12 \\
\hline \multicolumn{2}{|c|}{ Massa jenis udara $(\rho)$} & \multicolumn{2}{|c|}{ Luas sapuan $(\mathrm{A})$} & Jari-jari $(\mathrm{F}$ & \multicolumn{3}{|c|}{ Jari-jari yang digunakan $(\mathrm{R})$} \\
\hline \multicolumn{2}{|c|}{1,225} & \multicolumn{2}{|c|}{$\begin{array}{l}2.160 \\
1.620\end{array}$} & $\begin{array}{l}0.83 \\
0.72 \\
\end{array}$ & & 0.8 & \\
\hline
\end{tabular}

Setelah didapat jari-jari yang akan digunakan yaitu 0.8 meter dan kecepatan angin maksimum yang dipakai adalah $12 \mathrm{~m} / \mathrm{s}$ maka digunakan jenis bilah Taper dalam penelitian ini, selanjutnya dilakukan pembagian elemen. Dalam penelitian ini menggunakan 10 elemen, karena panjang bilah tergolong pendek hanya sebesar 0.8 meter maka tidak diperlukan pembagian elemen terlalu banyak. elemen ini berguna untuk proses manufakturing bilah itu sendiri dalam memudahkan pembuatan, jika memakai material kayu itu sangat diperlukan karena bilah yang akan dibuat dari kayu memerlukan referensi ukuran pembuatan dari setiap elemen yang ada. 
Tabel 4. Data geometri bilah airfoil SG6043

\begin{tabular}{cccccc}
\hline \multirow{2}{*}{ Elemen } & $\mathrm{R}$ & \multirow{2}{*}{ TSR Parsial } & Flow Angle & Twist & Chord \\
\cline { 2 - 2 } \cline { 5 - 6 } & $(\mathrm{m})$ & & (Degree) & $($ Degree $)$ & $(\mathrm{m})$ \\
\hline 0 & 0.17 & 1.49 & 22.608 & 19.61 & 0.077 \\
1 & 0.23 & 2.04 & 12.419 & 14.42 & 0.056 \\
2 & 0.3 & 2.59 & 14.074 & 11.07 & 0.044 \\
3 & 0.36 & 3.14 & 11.772 & 8.77 & 0.037 \\
4 & 0.42 & 3.69 & 10.102 & 7.1 & 0.031 \\
5 & 0.49 & 4.24 & 8.84 & 5.84 & 0.027 \\
6 & 0.55 & 4.8 & 7.853 & 4.85 & 0.024 \\
7 & 0.61 & 5.35 & 7.063 & 4.06 & 0.022 \\
8 & 0.67 & 5.9 & 6.416 & 3.42 & 0.020 \\
9 & 0.74 & 6.45 & 5.876 & 2.88 & 0.018 \\
10 & 0.8 & 7 & 5.42 & 2.42 & 0.016 \\
\hline
\end{tabular}

Didapat nilai sudut puntir pada elemen 0 yaitu $19.61^{\circ}$ hingga elemen 10 yaitu $2.42^{\circ}$. Nilai sudut puntiran ini cukup ekstrim khususnya pada manufakturing bilah penggunaan material kayu karena dapat mempersulit dalam pembentukan geometri bilah itu sendiri. Jika terlalu terpuntir maka diperlukan linearisasi garis untuk memudahkan proses manufaktur bilah. pada tabel 4 merupakan data geometri sebelum dilakukan linearisasi.

Setelah didapat data tersebut, maka selanjutnya dilakukan linearisasi sudut puntir dengan asumsi titik linearisasi chord yaitu pada $75 \%$, asumsi ini diambil berdasarkan panjang keseluruhan bilah agar sudut puntir bilah tidak terlalu runcing. Didapat persamaan dari garis linear tersebut serta nilai x dari persamaan dikalkulasikan dengan nilai jari-jari parsial (r). Untuk hasil uji yang bernilai negatif maka hasil tersebut tidak bisa diterapkan pada bilah turbin angin.

Tabel 5. Hasil pengujian variasi twist terhadap chord pada $75 \%$

\begin{tabular}{ccccc}
\hline \multirow{2}{*}{ Titik Linearisasi } & $\begin{array}{c}\text { Twist Linear } \\
\text { Sebelum }\end{array}$ & Chord Linear & Hasil Uji & Hasil Uji \\
& Degree $\left({ }^{\circ}\right)$ & $(\mathrm{m})$ & Twist & Chord \\
\cline { 2 - 3 } & $19.61--32.29$ & $0.077-0.016$ & Tidak & Lolos \\
\hline Twist 5\%, Chord 75\% & $17.76--15.68$ & $0.077-0.016$ & Tidak & Lolos \\
Twist 15\%, Chord 75\% & $15.68--7.34$ & $0.077-0.016$ & Tidak & Lolos \\
Twist 25\%, Chord 75\% & $13.78--2.92$ & $0.077-0.016$ & Tidak & Lolos \\
Twist 35\%, Chord 75\% & $12.15--0.47$ & $0.077-0.016$ & Tidak & Lolos \\
Twist 45\%, Chord 75\% & $10.77-0.91$ & $0.077-0.016$ & Lolos & Lolos \\
Twist 55\%, Chord 75\% & $9.60-1.69$ & $0.077-0.016$ & Lolos & Lolos \\
Twist 65\%, Chord 75\% & $8.59-2.12$ & $0.077-0.016$ & Lolos & Lolos \\
Twist 75\%, Chord 75\% & $7.73-2.34$ & $0.077-0.016$ & Lolos & Lolos \\
Twist $85 \%$, Chord 75\% & $6.98-2.42$ & $0.077-0.016$ & Lolos & Lolos \\
Twist 95\%, Chord 75\% & & & & \\
\hline
\end{tabular}

Dari hasil pengujian pada Tabel 5 didapat bahwa ada lima titik linearisasi yang tidak lolos uji karena bernilai negatif pada hasil uji sudut puntir (twist). Maka kelima hasil tersebut tidak bisa dilanjutkan untuk dianalisa menggunakan perangkat lunak Qblade. Untuk melihat hasil simulasi Cp terhadap TSR tersebut bisa dilihat pada Tabel 6 dan Gambar 3 berikut : 
Tabel 6. Hasil simulasi CP - TSR pada variasi sudut puntir (twist) dan chord pada $75 \%$

\begin{tabular}{ccc}
\hline Titik Linearisasi & Cp & TSR \\
\hline Twist 55\%, Chord 75\% & $52.2 \%$ & 4 \\
Twist 65\%, Chord 75\% & $52.1 \%$ & 4 \\
Twist 75\%, Chord 75\% & $51.9 \%$ & 4 \\
Twist $85 \%$, Chord 75\% & $51.8 \%$ & 4 \\
Twist 95\%, Chord 75\% & $51.6 \%$ & 4 \\
\hline
\end{tabular}

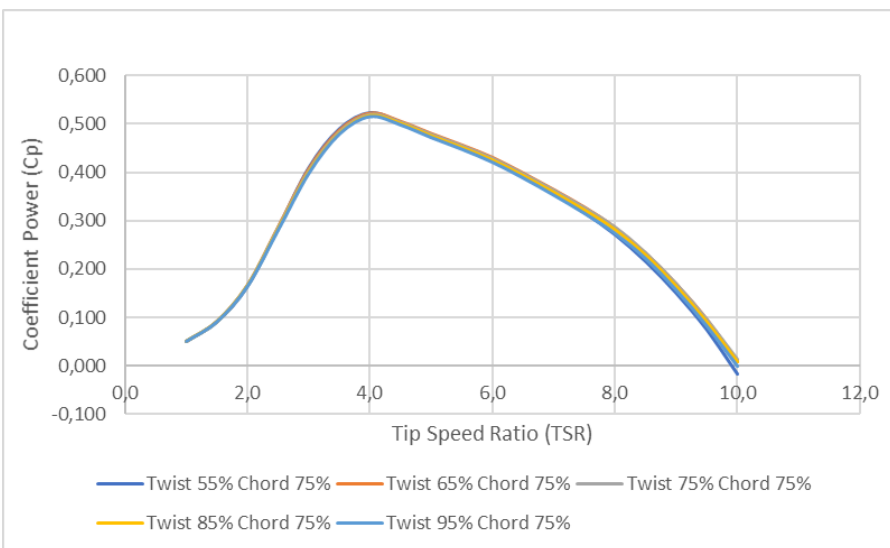

Gambar 3. Grafik simulasi CP - TSR pada variasi sudut puntir (twist) dan chord pada $75 \%$ menggunakan software Qblade

Berdasarkan hasil pengujian variasi sudut puntir (twist) dan chord pada 75\% didapat bahwa titik linearisasi sudut puntir (twist) pada 55\% menghasilkan coefficient power (Cp) sebesar 52,2\% dengan Tip speed ratio sebesar 3. Maka hasil pengujian linearisasi sudut puntir (twist) pada 55\% dipilih untuk proses perancangan selanjutnya yaitu variasi lineariasi lebar airfoil (chord).

Tabel 7. Hasil pengujian linearisasi sudut puntir pada $55 \%$ dan variasi chord

\begin{tabular}{ccccc}
\hline Titik Linearisasi & $\begin{array}{c}\text { Sebelum } \\
\text { Linearisasi (m) }\end{array}$ & $\begin{array}{c}\text { Sesudah } \\
\text { Linearisasi (m) }\end{array}$ & $\begin{array}{c}\text { Penambahan } \\
\text { agar 0,12 m }\end{array}$ & $\begin{array}{c}\text { Hasil } \\
\text { Uji }\end{array}$ \\
\hline Twist 55\%, Chord 5\% & $0.077-0.016$ & $0.120--0.089$ & - & Tidak \\
Twist 55\%, Chord 15\% & $0.077-0.016$ & $0.068--0.052$ & $0.120-0.000$ & Tidak \\
Twist 55\%, Chord 25\% & $0.077-0.016$ & $0.060--0.018$ & $0.120-0.042$ & Lolos \\
Twist 55\%, Chord 35\% & $0.077-0.016$ & $0.053--0.002$ & $0.120-0.065$ & Lolos \\
Twist 55\%, Chord 45\% & $0.077-0.016$ & $0.047-0.007$ & $0.120-0.080$ & Lolos \\
Twist 55\%, Chord 55\% & $0.077-0.016$ & $0.043-0.012$ & $0.120-0.089$ & Lolos \\
Twist 55\%, Chord 65\% & $0.077-0.016$ & $0.039-0.014$ & $0.120-0.095$ & Lolos \\
Twist 55\%, Chord 75\% & $0.077-0.016$ & $0.036-0.015$ & $0.120-0.099$ & Lolos \\
Twist 55\%, Chord 85\% & $0.077-0.016$ & $0.033-0.016$ & $0.120-0.103$ & Lolos \\
Twist 55\%, Chord 95\% & $0.077-0.016$ & $0.031-0.016$ & $0.120-0.105$ & Lolos \\
\hline
\end{tabular}

Dari hasil pengujian pada Tabel 7 didapat bahwa ada dua titik linearisasi yang tidak lolos uji karena bernilai negatif dan bernilai 0 (tidak memiliki bentuk airfoil diujung bilah) pada hasil penambahan angka agar chord tersebut berjumlah $12 \mathrm{~cm}$ untuk disesuaikan untuk ukuran pangkal bilah. Maka kedua hasil tersebut tidak bisa dilanjutkan untuk dianalisa menggunakan perangkat 
lunak Qblade. Untuk melihat hasil simulasi Cp - TSR pada linearisasi sudut puntir (twist) 55\% dan variasi chord dapat dilihat pada Gambar 4 dan tabel 8:

Tabel 8. Hasil simulasi CP - TSR pada linearisasi sudut puntir (twist) pada 55\% dan variasi chord

\begin{tabular}{ccc}
\hline Titik Linearisasi & Cp & TSR \\
\hline Twist 55\%, Chord 25\% & $52.6 \%$ & 4.5 \\
Twist 55\%, Chord 35\% & $52.2 \%$ & 4 \\
Twist 55\%, Chord 45\% & $50.6 \%$ & 3.5 \\
Twist 55\%, Chord 55\% & $52.2 \%$ & 4 \\
Twist 55\%, Chord 65\% & $48.5 \%$ & 3.5 \\
Twist 55\%, Chord 75\% & $50.2 \%$ & 4 \\
Twist 55\%, Chord 85\% & $48.1 \%$ & 3.5 \\
Twist 55\%, Chord 95\% & $47.9 \%$ & 3.5 \\
\hline
\end{tabular}

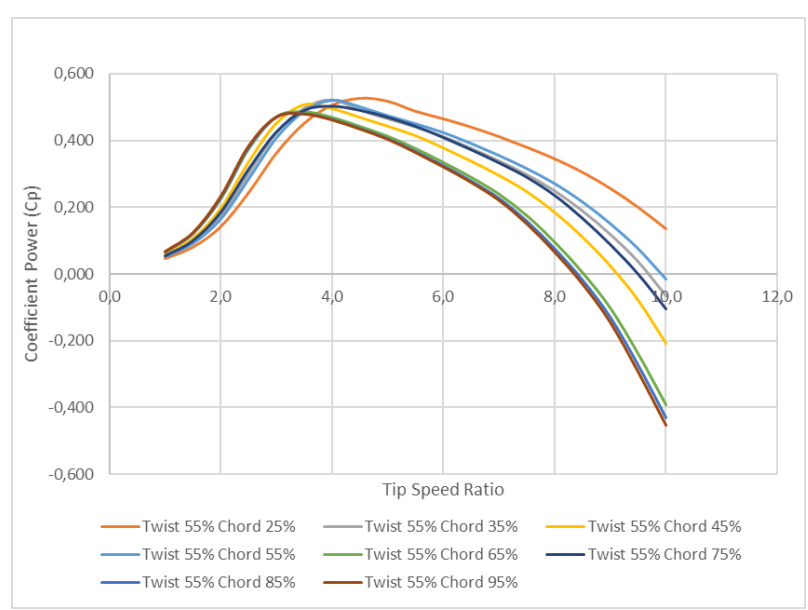

Gambar 4. Grafik simulasi CP - TSR pada sudut puntir (twist) 55\% dan variasi chord menggunakan perangkat lunak Qblade

Dari Gambar 4 dilakukan simulasi dengan menggunakan perangkat lunak Qblade yaitu Rotor BEM Simulation untuk melihat coefficient power (Cp) dan Tip speed ratio (TSR). Berdasarkan hasil simulasi pada tabel 8 variasi linearisasi chord didapat bahwa titik linearisasi chord pada 25\% menghasilkan coefficient power $(\mathrm{Cp})$ sebesar $52.6 \%$ dengan Tip speed ratio sebesar 4.5.

Pada generator yang dipakai yaitu memiliki spesifikasi TSD-500 memiliki pergerakan generator jika angin yang diterima pada bilah terlalu besar dan bilah tersebut berputar terlalu cepat maka sistem akan memutar generator beserta bilahnya melawan arah angin agar turbin aman dari kerusakan, tetapi jika turbin tetap diimplementasikan dengan bilah yang sebelum dilinearisasi sangat tidak efisien dikarenakan sistem perputaran generator tersebut dan pertimbangan lainnya adalah bentuk geometri bilah yang sangat tipis dapat menyebabkan keretakan dan patah dengan sangat cepat, maka grafik sesudah dilinearisasi sangat mungkin diimplementasikan karena dapat menjaga Tip speed ratio dari kecepatan putar, pada TSR 4-5 dapat menghasilkan Coefficient power (Cp) hingga $52.6 \%$. 
Tabel 9. Data airfoil yang akan dipakai pada desain bilah

\begin{tabular}{ccccc}
\hline \multirow{2}{*}{ No } & $\mathrm{r}$ & Chord $(\mathrm{m})$ & Twist & \multirow{2}{*}{ Airfoil } \\
\cline { 2 - 4 } & $(\mathrm{m})$ & $(\mathrm{m})$ & $($ degree $)$ & \\
\hline 0 & 0.17 & 0.12 & 10.77 & SG6043 \\
1 & 0.23 & 0.112 & 9.78 & SG6043 \\
2 & 0.3 & 0.104 & 8.8 & SG6043 \\
3 & 0.36 & 0.097 & 7.81 & SG6043 \\
4 & 0.42 & 0.089 & 6.83 & SG6043 \\
5 & 0.49 & 0.081 & 5.84 & SG6043 \\
6 & 0.55 & 0.073 & 4.85 & SG6043 \\
7 & 0.61 & 0.065 & 3.87 & SG6043 \\
8 & 0.67 & 0.058 & 2.88 & SG6043 \\
9 & 0.74 & 0.05 & 1.9 & SG6043 \\
10 & 0.8 & 0.042 & 0.91 & SG6043 \\
\hline
\end{tabular}

Data pada Tabel 9 dimasukan ke dalam perangkat lunak Qblade diantaranya jari-jari parsial $(\mathrm{r})$, chord (m), twist, dan airfoil yang digunakan, Pada Gambar 5 adalah input data pada perangkat lunak Qblade desain bilah taper SG6043 dan Gambar 6 adalah hasil perbesaran dari desain bilah taper SG6043 serta dimensi dari geometri.

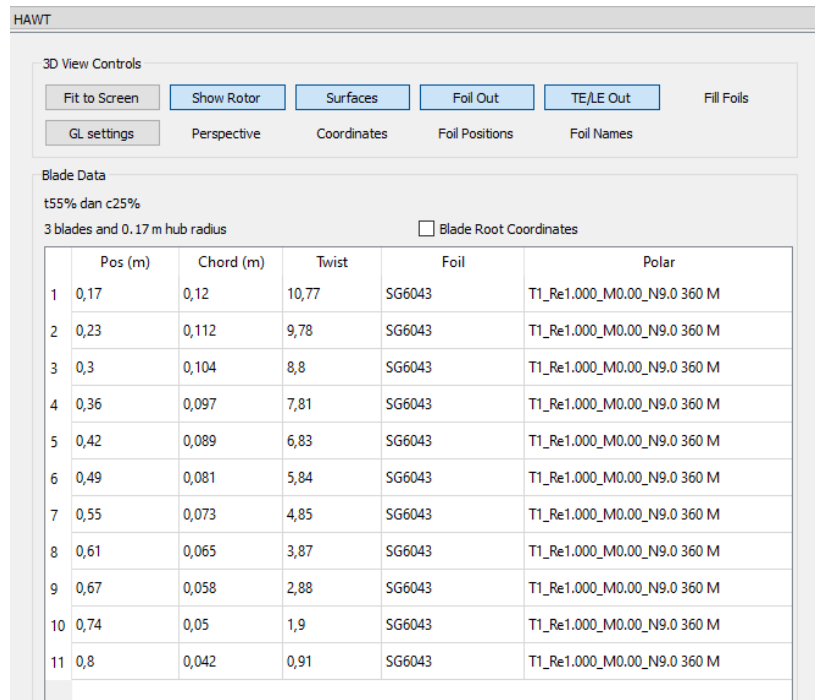

Gambar 5. Penginputan data airfoil pada perangkat lunak Qblade

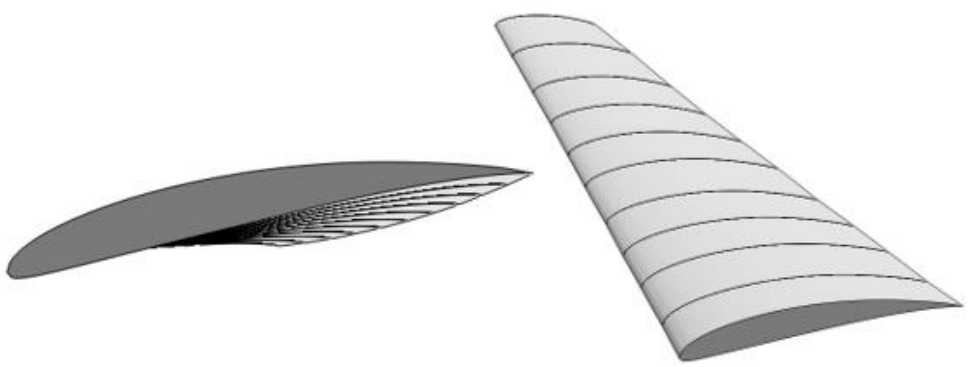




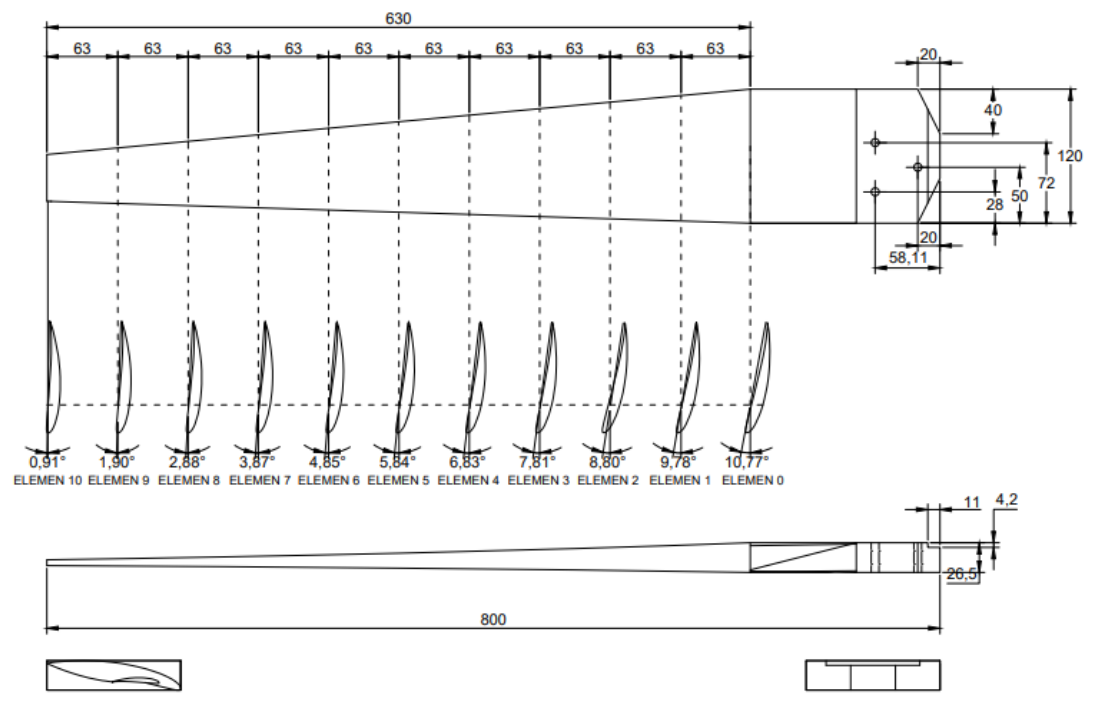

Gambar 6. Hasil desain bilah taper SG6043

\section{KESIMPULAN}

Berdasarkan hasil penelitian yang telah dilakukan mendapatkah hasil bahwa bilah airfoil SG6043 Taper dengan titik chord pada 75\% dan variasi sudut puntir pada 55\%, 65\%, 75\%, 85\%, 95\% didapat nilai tertinggi pada titik twist 55\% dengan hasil coefficient power (Cp) sebesar 52.2\% dan TSR sebesar 4. Lalu untuk hasil sudut puntir pada 55\% dengan variasi chord pada titik 25\%, $35 \%, 45 \%, 55 \%, 65 \%, 75 \%, 85 \%, 95 \%$ didapat hasil tertinggi pada titik twist $55 \%$ dan chord $25 \%$ dengan nilai coefficient power (Cp) sebesar 52.6\% dengan nilai TSR sebesar 4.5.

\section{UCAPAN TERIMA KASIH}

Ucapan terima kasih penulis kepada berbagai pihak yang turut mendukung dalam penelitian ini, terutama kepada Bapak Ing. Reza Setiawan, M.T. dan Oleh, S.T, M.T, sebagai pembimbing dalam penelitian ini

\section{DAFTAR PUSTAKA}

[1] L. Adam and M. T. Sambodo, "Indonesia’s Dynamic Electricity Power Sector: Investigating Need and Supply Performance,” Econ. Financ. Indones., vol. 61, no. 1, p. 53, 2015.

[2] Tim Sekretaris Jenderal Dewan Energi Nasional, "Indonesia Energy Out Look 2019,” J. Chem. Inf. Model., vol. 53, no. 9, pp. 1689-1699, 2019.

[3] Badan Meteorologi, Klimatologi, dan Geofisika, "Kecepatan Angin dan Kelembaban di Stasiun Pengamatan BMKG 2011-2015.” Badan Pusat Statistik, 2015.

[4] M. N. Habibie, A. Sasmito, and R. Kurniawan, "Kajian Potensi Energi Angin Di Wilayah Sulawesi Dan Maluku,” J. Meteorol. dan Geofis., vol. 12, no. 2, pp. 181-187, 2011. doi: 10.31172/jmg.v12i2.99.

[5] Y. Daryanto, "Kajian Potensi angin Untuk Pembangkit Listrik Tenaga Bayu," in BALAI PPTAGG UPT" 2020.-LAGG, 2007.

[6] A. Bachtiar, "Analisis Potensi Pembangkit Listrik Tenaga Angin PT. Lentera Angin Nusantara (LAN) Ciheras," J. Tek. Elektro ITP, vol. 7, no. 1, pp. 34-45, 2018. doi: 10.21063/jte.2018.3133706. 
[7] Lentera Bumi Nusantara, "Dasar - dasar Perancangan Bilah.” 2020.

[8] N. H. Sari and W. G. Laksamana, "Perancangan bilah tipe taperless pada kincir angin: Studi kasus di PT. Lentera Bumi Nusantara Tasikmalaya," Din. Tek. Mesin, vol. 9, no. 2, p. 104, 2019. doi: $10.29303 / \mathrm{dtm} . \mathrm{v} 9 \mathrm{i} 2.286$.

[9] H. Piggott, Windpower Workshop. 1997.

[10] C. Otieno Saoke, "Power Performance of an Inversely Tapered Wind Rotor and its Air Flow Visualization Analysis Using Particle Image Velocimetry (PIV),” Am. J. Phys. Appl., vol. 3, no. 1, p. 6, 2015. doi: 10.11648/j.ajpa.20150301.12 